\title{
Análise comparativa de clubes de futebol com escalões de formação de diferentes contextos
}

CDD. 20.ed. 796.06

796.33

http://dx.doi.org/10.1590/1807-55092015000300409

\author{
Artur J orge SANTOS* \\ Carlos Eduardo GONÇALVES*
}

*Faculdade de Ciências do Desporto e Educação Física, Universidade de Coimbra.

\section{Resumo}

No decorrer da sua existência e funcionamento os clubes estão sujeitos a influências provenientes do contexto onde estão inseridos, todavia também podem influenciar os sujeitos envolvidos no clube através da sua cultura organizacional. Pelas especificidades dos contextos dos clubes revela-se necessário obter dados sobre a sua cultura e o seu funcionamento para poder perceber os seus efeitos no envolvimento e desenvolvimento dos indivíduos. Para este artigo pretendeu-se a análise e comparação de três clubes de futebol de contextos diferentes, um clube profissional e dois amadores, em que um provém de meio rural e outro de meio urbano. Recorreu-se à observação participante e a entrevistas semiestruturadas para recolher os dados. A AAC-OAF diferencia-se dos clubes amadores pela sua orientação para o esporte de rendimento/espetacularização. Os últimos são suportados no voluntariado, dependendo mais das autarquias e políticas locais e revelam maiores dificuldades na angariação de voluntários, os quais aderem por amizade. A assunção dos cargos dirigentes nos clubes amadores são motivados pelo receio da extinção do clube. A estabilidade financeira da UCE contribui para mudanças na sua cultura e funcionamento organizacional. Todos os clubes demonstram falhas no processo de avaliação na implementação dos programas com vista ao desenvolvimento do jovem atleta, centrando-se esta essencialmente nos resultados desportivos obtidos.

PalavRas-CHAVE: Profissional; Voluntário; Rural; Urbano.

\section{Introdução}

A sociedade tem atribuído uma nova dimensão à atividade física e ao esporte, principalmente no que respeita à promoçấo da saúde e geração de valores importantes (e.g., desportivismo), com o intuito de contribuir para o desenvolvimento pessoal e comunitário. No entanto, há que ter em conta as especificidades culturais e contextuais das organizaçóes desportivas onde o indivíduo está inserido.

Segundo Gómez et al. ${ }^{1}$ as organizaçóes desportivas podem ser classificadas em três tipos, de acordo com as suas finalidades: corpos governativos desportivos, organizaçóes de eventos desportivos e entidades fornecedoras de esporte. Nos corpos governativos desportivos incluem-se as macroestruturas federativas (e.g., Federação Portuguesa de Futebol), as quais têm funçôes de regulamentaçãa, organização e coordenação das respetivas modalidades ${ }^{2}$. Estas organizaçôes sustentam-se em estruturas organizacionais com caráter regional (e.g., associações distritais/ regionais), que por sua vez se sustentam nas entidades fornecedoras de esporte. As últimas são na sua maioria clubes desportivos, os quais possibilitam a prática desportiva e outras formas de ligação ao esporte por parte dos indivíduos, como por exemplo atletas, treinadores e dirigentes. No decorrer do presente trabalho iremos referir-nos às entidades fornecedoras de esporte enquanto clubes, facilitando a leitura e a compreensão deste, ao mesmo tempo, que se é mais específico no estilo de entidade.

As organizações desportivas, mais especificamente os clubes desportivos, têm singularidades no seu funcionamento e acarretam algumas dificuldades na implementaçáo de políticas generalistas ${ }^{3}$. Pelo que a análise dos clubes sustentados no voluntariado ganha maior relevância quando se refere que este é o maior setor de trabalho voluntário e tem um grande impacto na economia de um país ${ }^{4}$ e são os locais que permitem à maioria dos atletas a participação 
desportiva. De fato, muitos atletas de elite iniciaram o seu processo de formação em clubes amadores.

No caso português, o futebol é a modalidade com maior número de atletas e clubes, apresentando algumas semelhanças com o sistema de Futebol francês, e algumas diferenças do brasileiro, visto que a Federação Portuguesa de Futebol é responsável máxima pela organização das competições regulares de futebol, nos diferentes escalóes etários e competitivos ${ }^{5}$. Na atualidade, esta modalidade é aquela que mais potencia a profissionalização do atleta em Portugal. No entanto, são escassos os dados relativos ao tipo de envolvimento desportivo, quer enquanto colaboradores ou atletas, e quais as relaçóes, as dificuldades e os efeitos que os clubes Portugueses têm, no desenvolvimento da sua atividade, nas pessoas envolvidas.

Nas últimas décadas verificou-se uma mudança no paradigma de gestão no esporte que levou ao desenvolvimento da estrutura e cultura organizacional. Com a integração de pessoal mais especializado nas estruturas dos clubes, principalmente nos clubes amadores, a estrutura organizacional destes é alterada ${ }^{1,6-7}$. No caso Português poder-se-á referir que estes são um fruto do processo educativo do nosso país, no que refere à formação de treinadores e de pessoal na área das Ciências do Esporte e Educação Física. Em algumas situaçóes este pessoal especializado é remunerado, noutras contribuem voluntariamente para o funcionamento da organização. Contudo, o indivíduo com a sua especialização contribui para um aumento da formalização do funcionamento organizacional. Um treinador com formação nas áreas das Ciências do Esporte e Educação tende a levar o conhecimento e comportamentos adquiridos através da sua formação para o contexto de prática, como é o exemplo, do registro de presenças dos atletas e programas de treino.

$\mathrm{O}$ crescimento em tamanho da organização é outro fator de desenvolvimento da estrutura organizacional é, essencialmente pelo número de membro e praticantes ${ }^{8}$. Isto leva-nos a considerar que um clube com maior dimensão, com mais modalidades e/ou equipes, e consequentemente, mais membros e atividades deverá revelar uma estrutura mais complexa, mais formal e com delegação de competências, quando comparado com um clube de menor dimensão e complexidade, como é o caso dos clubes amadores. Neste sentido, os clubes que integram as ligas profissionais devem apresentar uma estrutura organizacional diferente das dos clubes amadores.

A preocupação com a promoção dos níveis de atividade física dos jovens e de aumento do número de equipes envolvidas em competição não é indissociável da necessidade de recursos humanos para que tal se proporcione. Para aumentar os níveis de participação no esporte organizado existe uma dependência do aumento do voluntariado, para organizar, gerir e praticar esporte?. Uma vez que a maioria dos jovens detêm pouca autonomia e competências para desenvolver funçôes de gestão dos clubes, é importante que os adultos se disponibilizem a exercer tais funçôes (e.g., dirigentes, treinadores) no esporte jovem. Em estudos realizados noutros países, acerca do voluntariado nas organizaçóes desportivas, identificaram como característica comum, os voluntários serem do sexo masculino ${ }^{9-10}$, estarem envolvidos nestas por causa das suas crianças serem atletas ${ }^{11}$. Além de que, a sua motivação para ser voluntário no esporte são, comumente, instrumentais (e.g., adquirir mais experiência e fazer currículo) ou de altruísmo/moral (e.g., dar um retorno ao clube, ajudar a organização) ${ }^{10}$. Contudo, o envolvimento no esporte enquanto colaborador também se reveste de fatores negativos de motivação e pressão para exercer voluntariado, como é caso do risco de colapso do clube e que não haja mais ninguém para desempenhar as funções na organização.

$\mathrm{O}$ funcionamento dos clubes está condicionado às características do meio onde está implementado, e estes contextos exercem influências mútuas. A promoção da atividade física dos jovens com o intuito de desenvolver competências sociais e pessoais, pode ser feita com a parceria entre os clubes e as autarquias locais. As competências sociais disruptivas, que atualmente estão agravadas por uma situação de crise financeira, como é o caso de exclusão social, comportamentos agressivos e antissociais, desinteresse pela escola, estão no foco das políticas nacionais e internacionais. As diferenças entre áreas urbanas e rurais ${ }^{12}$, o fator da densidade demográfica ${ }^{13}$, bem como, as características socioculturais, políticas e econômicas são fatores provenientes do meio ambiente que afetam o funcionamento da organização desportiva ${ }^{14-15}$, e consequentemente, os indivíduos envolvidos nesta. Se por um lado a densidade demográfica (e.g., meio rural) pode afetar a capacidade de angariação de atletas para a prática desportiva, principalmente, no caso do futebol que é uma das modalidades desportivas coletivas que requer mais participantes. Por outro lado, esta pode ser um fator que limite o envolvimento de mais colaboradores voluntários no clube, por questôes de concorrência de tempo com outras atividades, bem como, as várias funçóes a exercer. Neste sentido coloca-se as seguintes questôes: será que os clubes desportivos amadores demonstram capacidade para recrutar colaboradores com formação profissional na área do esporte? Que 
critérios são utilizados para selecionar os treinadores e demais colaboradores?

No decorrer da implementação dos programas desportivos pelos clubes, estes podem apresentar desvantagens educacionais, podendo advir daí risco de desenvolvimento dos jovens. Os contextos onde os jovens atletas desempenham as suas funçôes são passíveis de exercerem influências no seu desenvolvimento, pelo que se revela de interesse analisar os contextos de prática desportiva ${ }^{16}$. Além de que, para intervir no funcionamento das organizaçóes desportivas, mais especificamente, nos clubes de futebol, é importante a obtenção de dados relativos ao seu funcionamento e cultura partindo de uma

\section{Método}

\section{Participantes}

Foram selecionados três clubes com camadas jovens de futebol de contextos diferentes, pertencentes ao Distrito de Coimbra, Portugal. Um clube inscrito na Liga Portuguesa de Futebol Profissional, e dois clubes amadores de nível distrital (um de contexto urbano e outro de contexto rural). Um dos requisitos era que os clubes tivessem experiência na colaboração em projetos de investigação.

Os contextos, rural e urbano, são definidos de acordo com o Instituto Nacional de Estatística de Portugal, em que o contexto rural entende-se por uma densidade populacional inferior a 100 habitantes por $\mathrm{km}^{2}$ e o contexto urbano é definido por uma densidade superior ao valor indicado.

O clube profissional é a Associação Acadêmica de Coimbra - Organismo Autônomo de Futebol (AAC-OAF), o clube amador de contexto rural é a Associação Desportiva de Poiares (ADP) e o clube amador de contexto urbano é o Uniāo Clube Eirense (UCE).

\section{Procedimentos}

Este é parte integrante de um projeto de pesquisa "Influências contextuais na prática de Futebol", aprovado pela Comissão de Ética da instituição dos investigadores. Os dirigentes foram contatados e deram autorizaçáo para participar no estudo. No caso do AAC-OAF o entrevistado foi o Diretor do Departamento Juvenil, enquanto nos clubes amadores foram entrevistados os presidentes do clube. As entrevistas semiestruturadas decorreram nas instalações do clube, perspectiva analítica. Assim, é passível a identificação dos diversos fatores de influências internas (e.g., finalidades, formalização, especialização, cultura do clube, história) e externas (e.g., densidade demográfica, relaçóes com outras entidades, políticas). E, consequentemente poder-se-á contribuir para a melhoria no funcionamento dos clubes e na definição e implantação de políticas desportivas mais adequadas às necessidades e realidade dos clubes.

O presente artigo pretendeu realizar uma análise comparativa entre entidades fornecedoras de esporte (Clubes) provenientes de contextos diferentes (Profissional; Amador de meio rural e de meio urbano) com camadas jovens de futebol.

num gabinete, procedendo-se ao registro áudio. Estas foram precedidas por uma visita guiada às instalaçóes do clube, registrando-se as observaçóes de campo no respectivo diário de campo. A coleta de dados contou em todos os momentos com uma especialista da área das Ciências da Educação e com o investigador principal. O conteúdo das entrevistas foi utilizado somente após a permissão do participante, através do Termo de Consentimento Livre e Informado.

\section{Coleta dos dados}

Procedeu-se ao diagnóstico dos clubes numa perspectiva da teoria organizacional com base no modelo analítico apresentado por Ferreira e Martinez ${ }^{17}$, recorrendo ao método de observação participante, combinando a observação direta (infraestruturas, modelo de organização, discurso), análise documental (estatutos, regulamentos e comunicados disponibilizados, "website/blog" do clube) e a entrevistas semiestruturadas a dirigentes do clube (há pelo menos dois anos). O processo de coleta dos dados decorreu sempre com a presença de dois investigadores.

\section{Análise dos dados}

Os dados recolhidos na entrevista semiestruturada foram transcritos "verbatim" para texto e, posteriormente, submetidos à análise de conteúdo ${ }^{18}$, através da organização e codificação dos dados em blocos temáticos comuns e das categorias. O bloco influências internas inclui: a) Gestáo e planejamento estratégico (objetivos, finanças); b) abordagens das 
relaçóes humanas (e.g., recrutamento, colaboradores, coesão grupal); c) eficácia organizacional (e.g., metas, finalidades, avaliação, relatórios); d) liderança (tomada de decisão, competências/poderes); e) cultura organizacional (e.g., história, datas, pessoas relevantes, rituais e festas). Já o bloco temático influências

\section{Resultados}

Através da análise documental verifica-se que a AAC-OAF apresenta-se como o clube mais antigo (datando a sua fundação em 1876), comparativamente, à ADP (1940) è̀ UCE (1964). Com recurso ao método de observação constatamos que a AACOAF tem uma academia de futebol, construída de raiz, com dois campos de relva sintética e um de relva natural. Além disso, a equipe profissional utiliza o estádio municipal para os jogos na sua competiçẫo. As equipes dos escalóes de formação também costumam utilizar campos de outros clubes da zona enquanto visitados. Nas infraestruturas da academia, existem espaços destinados a funcionalidades específicas, como é caso da sala de musculação, de fisioterapia, quartos, refeitório, sala imprensa, sala de análise de jogos. A sala de musculação encontra-se disponível para os atletas dos escalóes de formação, sob orientação de um especialista.

Nos clubes amadores as infraestruturas indiciam que foram alteradas e adaptadas ao longo da vida do clube, consoante as possibilidades financeiras e materiais às necessidades surgidas no clube. No caso específico da ADP, esta apresenta um campo de terra batida e três vestiários. A UCE apresenta um campo de relva sintética, cinco vestiários, uma sala para fisioterapia. Estes dois clubes também apresentam uma sala para a direçẫo e um bar.

$\mathrm{Na}$ entrevista semiestruturada ao Coordenador Técnico do Departamento Juvenil, da AAC-OAF, podemos afirmar que o rendimento desportivo é o fim primário, tendo em conta o número de referências aos outros fins de caráter sociocultural e educativo da organização, os quais estão espelhados nos estatutos do clube.

\section{Coordenador Técnico do Departamento Juvenil - $A A C-O A F$}

Agora a nossa principal missão é o quê, formar com qualidade para levar atletas para a equipe principal.

Tentar vencer as séries. Depois. Tentar chegar às fases finais e ser os campeões a nível do distrito. externas compreende as resistências e influências externas. Os resultados obtidos da análise de cada clube foram posteriormente comparados com os dos outros clubes. A análise do conteúdo foi procedida por dois investigadores, seguindo as recomendações de FLICK ${ }^{18}$.

Verificou-se ainda que, a AAC-OAF detém relaçóes com os colaboradores de poder misto (remunerativo e normativo). Neste clube existem trabalhadores profissionais, com vínculo laboral (e.g., jogadores profissionais, roupeiros, treinador equipe sênior) e colaboradores voluntários (e.g, treinadores dos escalōes de formação, "team manager"), os quais se mantém ligados por fatores instrumentais (enriquecimento do currículo) e/ou recompensas monetárias (não são consideradas como remuneração, mas sim como ajudas de custo).

Nos seus quadros de funcionamento, encontram-se profissionais e colaboradores voluntários com formação especializada. É comum recrutar colaboradores que sejam estudantes ou licenciados em Ciências do Esporte e Educação Física para desempenhar as funçôes de treinador, treinador adjunto, preparador físico e analista de jogos. $\mathrm{O}$ funcionamento da AAC-OAF caracteriza-se por uma média formalizaçáo, existindo manuais para os atletas e dirigentes e, relatórios de acompanhamento do desenvolvimento do jovem atleta. Denotou-se, ainda, uma composição de grupos homogêneos por departamentos, dentro da estrutura organizacional (e.g., direção, departamento médico, departamento de formação - futebol 7 , futebol 11) com um grau de intimidade primário em cada grupo, mas secundário no que respeita ao relacionamento entre estes e a base de trabalho e o topo hierárquico. Coordenador Técnico do Departamento Juvenil - $A A C-O A F$

[...] Em termos de estrutura há o presidente da instituição, há o vice-presidente para área da formação.....E abaixo desse, sou eu, como diretor geral... Tenho uma abrangência em quase todas, os departamentos e, em tudo o que se passa relativamente ao futebol juvenil. Desde de organizaçáo do departamento, desde a parte logística. De utilizaçẫo, condiçôes, de treinadores. Gabinete de prospecçáo, do departamento médico, tenho um pouco de abrangência sobre, sobre essas áreas.[...]. 
A AAC-OAF utiliza uma padronização dos processos de trabalho, no que respeita à distribuição das funçóes estabelecidas (e.g., burocracia da equipe - ficha de jogos, inscriçóes, mensalidades; roupeiro; treinadores), mas revela alguma autonomia na execução das diversas funçôes. No caso dos treinadores o processo de treino e competição é definido por eles próprios, demonstrando autonomia na implementaçáo e desenvolvimento do trabalho com os atletas da sua equipe. Esta descentralização horizontal e vertical tem como centro operacional o Coordenador Técnico do Departamento de Formação, constituindo uma parte chave da organização, localizando-se como elemento conector do topo (direção) com a base (treinadores, dirigentes, atletas). Neste clube, o estilo de comunicação entre os colaboradores é misto, uma vez que se revela formal no topo hierárquico, mas essencialmente, entre os colaboradores da base da pirâmide e os elementos do topo. Enquanto na base da pirâmide (e.g., treinadores, atletas) o estilo de comunicação é informal. Apesar da existência de formalidade na comunicação entre os diferentes colaboradores, esta pode ser realizada ascendentemente (base-topo), descendentemente (topo-base) e lateralmente (entre colegas de funçôes). No entanto, os sentidos de comunicação mais comuns é a comunicação lateral, nos escalóes de formação e entre treinadores, e a ascendente, dos treinadores até ao diretor da formação juvenil e deste para a direção.

As mudanças no decorrer da existência da AACOAF, nas últimas três décadas, foram de primeira ordem, planejadas e implementadas de modo incremental. O clube conseguiu responder às exigências do meio, encontrando-se numa fase de equilíbrio e estabilidade. Para os seus escalóes de formação são referidas metas e objetivos gerais, com os objetivos específicos a serem estabelecidos, na sua maioria, informalmente e descentralizada para cada grupo técnico responsável por uma equipe. Apesar da AAC-OAF não demonstrar nenhum sistema de avaliação da concretização das metas e objetivos, os quais estão claramente orientados para o rendimento desportivo, utiliza-se os resultados obtidos no decorrer da época desportiva como dados de avaliação sobre o desempenho e alcance das metas.

É de referir que este clube apesar de ser profissional tem uma identidade e cultura peculiar no que respeita à educação e cultura, demonstrando uma ligação muito forte à Universidade e à cidade. $\mathrm{Na}$ entrevista também foram referidas outras influências externas, as quais se prendem com questões econômicas (e.g., custos de serviços, situação da economia local e nacional) e políticas (e.g., legislação, infraestruturas desportivas).

\section{Coordenador Técnico do Departamento de For- mação - AAC-OAF}

[...]Se tiverem um bom impacto na imprensa, se tivermos atletas a serem chamados à seleçáo...É mais fácil sensibilizar quem está no futebol profissional.[...] E a câmara apoiou, suportou todo o torneio em si... portanto, as deslocaçôes das equipes cá. Como a estadia. [...] Também pontualmente há empresas que aqui vêm, solicitam o espaço, e utilizam esta sala. Temos protocolos com equipes, com um colégio, que vêm aqui, fazem o trabalho deles [...].

Como esperado, os clubes amadores analisados são organizaçóes assentes na colaboração voluntária. Apesar de terem uma base formal, organizada na sua constituição e registro legal, no seu funcionamento prático estes são muito informais, apresentando um tipo de estrutura simples ou primária. O contato entre os colaboradores da organização é informal e estes revelam características heterogêneas entre si. A inclusão dos colaboradores no clube é essencialmente feita através de laços de amizade entre os elementos. Contudo, sáo referidas dificuldades em recrutar colaboradores impossibilitando a procura de indivíduos com características similares (e.g., formação, experiência) que poderiam potenciar o desenvolvimento do clube e dos jovens. Este fato é mais referido na ADP, o qual está inserido num local com uma densidade demográfica menor. No caso do clube amador de contexto urbano, esta estabelece critérios no recrutamento de colaboradores para treinador de futebol dos escalóes de formação, como é a formação na área do esporte, da pedagogia ou com experiência desportiva no futebol.

Da entrevista semiestruturada ao presidente da ADP, depreende-se que a sua finalidade prende-se com a participaçáo desportiva dos jovens pelo seu valor social, educativo e de saúde.

\section{Presidente da ADP}

Os adultos ficarem na melhor classificação possível. Os jovens...Que tenham um espaço e que venham jogar futebol e não estejam a fazer outras coisas. Às vezes más

Além desta finalidade, na UCE também se refere o rendimento desportivo como finalidade, apesar de se poder considerar como secundária.

\section{Presidente da UCE}

A finalidade, além do esporte ser o fundamental... a maior fonte de motivaçẫo acredito que para os jogadores é mesmo... ganhar, ganhar, estar em primeiro. 
Uma das diferenças entre os clubes amadores analisados é a centralização da tomada de decisão. No caso do clube amador de contexto rural existe maior centralização, com o presidente do clube a estar envolvido na maioria dos processos de tomada de decisão (e.g., aquisição de bolas, falta de equipamento, abertura das instalaçóes), com a exceçáo do processo de treino e competiçâo. Enquanto que na UCE verifica-se no discurso uma descentralização de funçôes de modo formal a nível horizontal (na direção há vice-presidentes com as suas áreas) e a nível vertical (direção, departamento de futebol - futebol adulto; futebol de formação, departamento de outros esportes).

A UCE é o clube analisado no presente estudo que mais modalidades desportivas disponibiliza, contando-se cinco: futebol, natação, Kempo, aeróbi$\mathrm{ca}$, ginástica. Enquanto os outros clubes observados apenas oferecem a modalidade desportiva de futebol. A AAC-OAF conta com mais equipes nos escalóes de formação, num total de 14, quando comparamos com as equipes de futebol dos escalóes de formação dos clubes amadores, que apresentam ambos seis equipes.

Os clubes amadores analisados demonstram uma comunicação organizacional informal entre os seus colaboradores, com esta a ser realizada em todos os sentidos (ascendente, descendente e lateral) existindo facilidade dos atletas e treinadores interpelarem o topo hierárquico, uma vez que estas organizaçóes compreendem apenas dois níveis estruturais, tendo uma menor complexidade e burocracia. Os objetivos financeiros e algumas metas a médio e longo prazo nos clubes amadores são definidas de modo informal, pouco ou nada apurados numa formalização que possibilite a correta avaliação da sua execução no decorrer do tempo. Estes demonstram uma inexistência de um processo de avaliação do trabalho realizado pela organização, pelos colaboradores e dos contributos que o serviço prestado tem nos jovens praticantes.

Presidente da UCE

"Sim, fazemos. Sempre mais para o final...Sempre no final de cada época fazemos um balanço. E depois, aí., no início, damos...quais são as ideias gerais, os objetivos que pretendíamos...

\section{Presidente da ADP}

Não há aqui nenhuma (sorriso)... não acabam por ser muitos. Mas também, com os treinadores e todo isso. Não há avaliação, nem nada.

Nestes clubes amadores a mudança organizacional tem sido alcançada através de alteraçóes de pequeno alcance, isto é, de primeira ordem, consoante as exigências limite do momento, bem como, das restriçôes existentes. Estas demonstram fraca estabilidade, principalmente financeira, devido às exigências econômicas atuais, necessidades de investimento para potenciar a oferta desportiva e falta de planejamento a longo prazo. Os Clubes Amadores referem influências externas sociais (e.g., envolvimento da comunidade no clube e nas suas atividades), políticas (e.g., apoios Municipais em infraestruturas ou monetários), culturais (e.g., a cultura da comunidade local e os interesses divergentes da população) e econômicas (e.g., situação financeira de patrocinadores, famílias).

Porém, a Presidente da UCE refere que tem vindo a sentir um aumento do número de sujeitos a aderir nos seus serviços desportivos mas, ao mesmo tempo, sente uma diminuição do envolvimento desportivo no clube em cargos de gestão ou outras funções de colaboração. Mais preocupante é o fato do Presidente da $A D P$ referir que verifica uma diminuição nos dois tipos de envolvimento no clube, isto é, de atletas e dirigentes. Relativamente às influências externas de carácter político a UCE demonstra sinergias com a autarquia e com outras instituiçóes governamentais para a construção e utilização de diferentes espaços desportivos, como é o caso do relvado sintético e das piscinas, e obtençáo de apoios monetários.

\section{Presidente da UCE}

[...] este terreno é um terreno da junta de freguesia, não é nosso. Tá cedido ao clube por 50 anos. Por 50 não, por $100 \ldots$ O sintético foi oferecido pela Câmara Municipal...Depois as outras instalaçóes que utilizamos, são as piscinas... que é propriedade da Câmara. Que... nós temos concessão de espaço[...]

A ADP demonstra uma maior dependência financeira externa, recorrendo aos apoios monetários Municipais para despesas correntes (e.g., transportes, água, luz, gás) e a patrocínios de outras entidades. $\mathrm{O}$ próprio clube não demonstra uma estratégia e planificação para o seu desenvolvimento a longo prazo, apresentando algumas linhas orientadoras definidas de forma informal para o período de um mandato no clube (dois anos). Esta falta de planificação também é refletida pela falta de articulação com a autarquia no que respeita aos apoios e protocolos com o Município, uma vez que os apoios são cedidos irregularmente ao longo do tempo e não existem protocolos para utilização de espaços desportivos ou com vista à promoção da atividade física. Neste sentido, o Clube Amador de contexto Rural está limitado, em termos de infraestruturas, ao seu campo de futebol, sem no entanto poder proceder à utilização e/ou exploração de outros 
espaços existentes na localidade (piscina, pavilhão gimnodesportivo, quadra de tênis). $\mathrm{O}$ apoio prestado pelo Município à $\mathrm{ADP}$ tem sido inconstante ao longo dos anos devido à ultrapassagem do limite de endividamento permitido por Lei da Câmara Municipal, o que levou a cortes sucessivos ano após ano.

No que respeita a outras influências políticas referidas pelos presidentes dos Clubes Amadores estão relacionadas com a legislação referente ao esporte, bem como os regulamentos e regras provenientes da Federação e da Associação de Futebol Distrital. Uma das dificuldades sentidas pelos presidentes dos Clubes Amadores é o dever de cumprir determinadas obrigaçóes financeiras para com a Associação de Futebol Distrital (taxas de jogos, aquisição de bolas, multas), a qual consume dinheiro que poderia ser destinado para a promoção e manutenção do fornecimento de serviços e programas desportivos (e.g., mais modalidades desportivas, mais formação dos treinadores), bem como, para o desenvolvimento da organização (e.g., infraestruturas).

\section{Presidente da UCE}

[...] sobrecarga da associação de futebol.“ “[...] agora para as inscriçôes não chegam se for preciso $4.000 €[\ldots]$.

As maiores críticas vêm principalmente das pessoas da terra, que nem sequer são sócios ou coisa que valha. Mas se calhar as maiores críticas são das pessoas. Que nem passam cá o seu tempo, mas são os primeiros a apontar o dedo.

\section{Presidente da $A D P$}

É, a própria associação. O próprio tarifário é elevado para as capacidades dos clubes.

E tu vês como é que isto está, cada vez há empresas a fechar mais. As pessoas são sempre as mesmas, as caras, aos domingos, nos treinos, os pais. São sempre as mesmas pessoas.

O estado econômico do país reflete-se na situação financeira das empresas e entidades governamentais que poderiam apoiar os clubes. Contudo, nos períodos de crise econômica o tecido empresarial tem a tendência para se retrair, acabando pelos clubes e outras instituiçôes de cariz local (e.g., Instituições Particulares de Solidariedade Social - IPSS) a concorrerem entre si na obtenção destes recursos (e.g., financeiros e gêneros).

Diretor Técnico do Departamento de Formação da $A A C-O A F$

[...] economicamente. Todas aquelas instituiçóes, digamos, empresas que nos possam apoiar, estáo a passar um período difícil. E os apoios, são, são difíceis.

\section{Presidente da ADP}

Depois temos as empresas, temos algumas que, que nos ajudam bastante.

\section{Presidente da UCE \\ [...]vamos mantendo o contato, de algumas em- presas, também. (...) e pronto, que nos apoiam ex- ternamente, a nível financeiro, ou em gêneros[...].}

\section{Discussão}

O presente estudo pretendia analisar e comparar o funcionamento e a cultura de três clubes de contextos diferentes. Como esperado, verificou-se que os Clubes Amadores apesar das suas diferenças, principalmente no que respeita à sua área demográfica e relaçóes externas, nutrem mais semelhanças entre si do que com a AAC-OAF.

Já era expectável que os Clubes Amadores apresentassem uma estrutura simples, visto que esta é uma das principais características das organizaçóes desportivas de caráter local ${ }^{8,14}$. Os níveis de especialização, centralização e formalização da UCE levam a referir que este clube encontra-se num nível intermédio entre a estrutura simples do Clube Amador do contexto Rural e a estrutura de burocracia profissional da $\mathrm{AAC}-\mathrm{OAF}^{19}$. É de referir que apesar das diferenças verificadas a estrutura da UCE está mais próxima da primeira no que respeita ao seu funcionamento prático e tácito. A centralização da decisão na estrutura simples potencializa tomadas de decisão rápidas e pode atrair colaboradores que preferem trabalhar num ambiente não burocrático e com um sentimento de missão. No entanto, ao centrar-se a decisão numa só pessoa, que normalmente é o presidente do clube, pode-se colocar entraves ao desenvolvimento da organizaçáo pela pretensáo de manutençáo do poder de decisão ou por impedimento de decisão do vértice (e.g., doença, ausência) ${ }^{14}$.

A facilidade de contato entre os diferentes colaboradores e pessoas envolvidas nos clubes pode potenciar o capital social e econômico (e.g., coesão comunitária, emprego e desempenho $)^{20}$, as relaçóes interpessoais e o sentimento de apoio por parte dos jovens ${ }^{21}$. Os atletas ao terem maior facilidade em contatar e se relacionar 
com adultos relevantes (e.g., dirigentes, treinadores) para as suas vidas, potencia a aquisição de competências sociais. Uma relação positiva entre treinador-atleta é fundamental para promover o desenvolvimento do jovem indivíduo ${ }^{22}$. Os atletas destes meios, apesar das desvantagens a nível de infraestruturas e de formação dos treinadores, podem revelar mais e melhores características de desenvolvimento pessoal e social do que os atletas da AAC-OAF. Contudo, os presidentes dos Clubes Amadores não percepcionam grande envolvimento da comunidade nas atividades do clube. Isto leva a sugerir que existe um afastamento das funçóes estatutárias dos clubes decorrendo da limitação de oferta de programas e atividades. $\mathrm{E}$ ao mesmo tempo os clubes sentem uma falta de adesão às atividades desportivas e de voluntariado. As alteraçóes econômicas sentidas pela população portuguesa, como é o caso, da redução do poder de compra, podem contribuir para esta diminuição.

A AAC-OAF estabeleceu uma estrutura mais complexa e com maior especialização devido a fatores como o crescimento em tamanho (e.g., número de sócios, número de atletas, colaboradores) e a inclusão de colaboradores profissionais especializados (e.g., licenciados em Ciências do Esporte), contribuindo para tal o aumento do profissionalismo do meio futebolístico. Estes resultados vão de encontro ao verificado por Gómez et al. ${ }^{1}$ Thibault et al. ${ }^{7}$. Segundo MinTZBERG $^{14} \mathrm{o}$ aumento do nível de profissionalização permite uma maior autonomia e a estandardizaçáo do trabalho, refletindo-se esta autonomia no contexto de treino e competição das diferentes equipes do clube. No entanto, é de realçar que o aumento da burocracia pode levar a que os colaboradores voluntários sejam vistos como trabalhadores não remunerados ${ }^{6} \mathrm{e} \mathrm{ser} \mathrm{um}$ fator de afastamento dos voluntários, os quais têm como característica o gosto em trabalhar em ambientes informais ${ }^{21}$. Neste sentido, futuros estudos devem analisar as percepçóes dos colaboradores relativamente ao funcionamento, finalidades e objetivos do clube.

Os dirigentes desportivos, os treinadores e demais devem pautar-se por valores e comportamentos positivos, podendo potenciar os efeitos do esporte no desenvolvimento do jovem atleta, quer a nível de desempenho quer no âmbito pessoal. Uma vez que o presente estudo apenas teve como participantes cargos dirigentes e não outras funçōes no clube torna-se interesse no futuro analisar as percepçôes e características dos colaboradores, principalmente dos voluntários, de clubes profissionais.

Analisando a AAC-OAF com base nos critérios de fins de WorsLey ${ }^{23}$ podemos considerá-lo uma organização de trabalho, uma vez que foi dado mais ênfase ao desempenho desportivo, enquanto os Clubes Amadores referem uma valorização do trabalho para a comunidade local e do esporte como meio educativo para jovens, podendo-se caracterizar por uma organização de benefício mútuo. O presente estudo reforça o de Heinila ${ }^{24}$ que verificou que o principal fim dos clubes, de nível local e regional, era de benefício mútuo. A estabilidade e preparação da AAC-OAF permitiu-lhe definir finalidades orientadas para o rendimento, as quais começam a ser referidas na UCE, e que podem vir a influenciar a cultura e o desenvolvimento da organização, o desempenho dos membros, bem como, as suas atitudes e valores ${ }^{25}$. Contudo, é de ter em atenção que contextos desportivos que promovam um clima mais orientado para o rendimento (e.g., resultados desportivos) estão mais propensos a promover o abandono desportivo dos atletas ${ }^{26}$. A exigência de vitórias, a percepção de sucesso e as expectativas sobre o papel do treinador também são fatores de "burnout" dos treinadores ${ }^{27}$. A pressão para ganhar, o requisito de ter que ajudar na vitória da equipe, a pretensáo de obter reconhecimento por outro pode potenciar um desenvolvimento negativo, como é o caso da adoção de atitudes e valores antissociais e antidesportivas pelos atletas ${ }^{28}$, bem como, fatores de "stress" para os treinadores (e.g., conflito, pressão, expectativas $)^{29}$ e pressão dos pais nos atletas ${ }^{30}$.

No esporte de competiçáo é natural que se tenha que potenciar o rendimento do atleta visto que há sempre o intuito de superar o adversário, mas ao mesmo tempo isto náo deve ser feito com recurso a atitudes que desvirtuem os princípios éticos do esporte, os quais devem ser fomentados para potenciar o desenvolvimento positivo do atleta.

É de realçar que as organizaçóes estudadas encontram problemas em adotar um modelo de planificação que defina metas específicas, principalmente no que respeita no desenvolvimento pessoal e atlético dos indivíduos, bem como a nível de funcionamento enquanto clube. Além das falhas na planificação, os Clubes Amadores demonstram dificuldades em implementar práticas básicas de gestão (e.g., planificação a médio e longo prazo), reforçando a ideia que independentemente do tipo de organização os dirigentes desportivos apenas enfatizam metas de curto prazo ${ }^{31}$, isto é, ano após ano consoante os resultados finais dos campeonatos das suas diversas equipes. CAVICHIOLLI et al. ${ }^{32}$ referem que os pais muitas das vezes consideram que "um gênio e futuro craque do futebol não podem começar simplesmente no campinho do bairro ou em 
qualquer time de escola. A opção de aprendizagem logo recai no clube, e este não pode ser qualquer clube" (p.635). Contudo, visto que existem falhas na avaliação do desenvolvimento do atleta como é que os atletas e pais podem optar por clubes distintos? É certo que na AAC-OAF existe um processo de seleção de talentos para participarem nos escalóes nacionais, a partir dos 12 , tem um sistema de recrutamento de jovens jogadores, pelo que claramente aposta na formação para carreira profissional daqueles que lhes podem render "frutos".

Os pais dos atletas ao atribuírem importância à área educacional, principalmente no acesso a um curso de ensino superior ${ }^{32}$, revela que os clubes devem contribuir para o desenvolvimento integral do jovem. Apesar do intuito dos Clubes Amadores serem na sua essência de benefício mútuo e enquanto meio educativo não formal (promoção de atividade física e de valores pró-sociais), a falta de planificação e avaliação para este objetivo náo permite averiguar a concretização deste, surgindo a questão: como é que os clubes avaliam o desempenho dos treinadores no seu papel de agentes educadores dos futebolistas? $\mathrm{O}$ modelo lógico para o desenvolvimento positivo dos jovens através do esporte desenvolvido por WELLs e ARTHUR-BANNING ${ }^{33}$ pode ser um modelo para desenvolver o trabalho dos dirigentes desportivos, através de esquemas e de definição de recursos/“inputs”, atividades, “outputs”, resultados, impacto.

Isto permitirá ter uma perspectiva longitudinal do trabalho realizado e os resultados obtidos pelo clube, permitindo uma análise organizacional. Será interessante verificar as influências sofridas no decorrer da existência e funcionamento do clube ao longo do tempo, para compreender as adaptaçóes que realizaram ao longo do seu funcionamento.

O baixo grau de formalidade apresentado pelos Clubes Amadores leva a um vazio das linhas orientadoras, não permitindo uma análise, execução e balanço do trabalho desenvolvido. Esta falta de planejamento a médio e longo prazo não é um fator determinante da ineficácia da organização desportiva, mas é um fator que dificulta a criação de melhores condições para o seu funcionamento ${ }^{34}$.

Isto leva-nos a sugerir que para a continuidade da existência dos Clubes Amadores estes vão-se valendo de um espírito comunitário e de valor histórico local do clube, aparentando uma pressão negativa para tal envolvimento. Isto é, os elementos envolvem-se e suportam a existência do clube com receio de que se não assumirem as funções mais ninguém as faça e assim colapse ou dificulte o funcionamento do clube.
Se seguirmos os indicadores de oferta desportiva utilizados por PAPAdIMITRIOU ${ }^{8}$, a ADP e a AAC-OAF, que se cingem apenas à modalidade de futebol, com uma equipe competitiva (sênior) e academia para novos atletas, pode-se considerar como um desempenho muito fraco de fornecimento de serviços, apesar da AAC-OAF demonstrar um número superior de atletas de futebol do que os Clube Amadores juntos. A dimensão da AAC-OAF e a capacidade de obtenção de fundos (e.g., direitos televisivos, "merchadising") permitem-lhe a orientação para o rendimento desportivo, para uma matriz mais espetacularizada, com uma especialização do trabalho nesta modalidade visando, nos escalóes de formação, providenciar atletas para o mercado futebolístico.

No caso da ADP, a baixa oferta desportiva pode dever-se a problemas no que respeita à definição de políticas objetivas em relação ao mercado servido e a resistências externas por parte das autoridades locais, como é o caso de falhas na concessão de instalações desportivas públicas, implementação de programas e atribuição de subsídios. A irregularidade dos apoios atribuídos aos clubes, também foi um constrangimento verificado nos clubes Gregos analisados por Papadimitriou ${ }^{8}$. Isto leva-nos a sugerir uma tendência transcultural entre estes países do Sul da Europa. Os referidos fatores restringem a ADP, levando a operar com pouca variedade dos programas desportivos oferecidos, o que por sua vez lhe coloca dificuldades na angariação de fundos, limitando o seu orçamento.

Contrariamente, a UCE adaptou-se às exigências do meio no que respeita à prática desportiva, através de sinergias com outras entidades, principalmente com as autoridades locais, oferecendo cinco programas desportivos, ao mesmo tempo que mantinha ou melhorava a sua viabilidade financeira e potenciou o envolvimento de indivíduos na organização e no esporte. Neste sentido, podemos referir que um funcionamento deficitário na colaboração entre clubes e autoridades locais pode colocar em causa a aplicação de programas desportivos, com efeitos no desenvolvimento dos indivíduos, dos clubes e, consequentemente, da comunidade. Em Portugal, comparativamente com o Brasil ${ }^{5}$, a competição de nível amador (de várzea ou comunidade), nos escalóes mais baixos, são organizados pelas Associações de Futebol regionais, que estão sob alçada da Federação Portuguesa de Futebol. Será importante em futuros estudos analisar esta relação institucional dos clubes com as autoridades locais e/ou as associaçóes distritais, para poder definir políticas que auxiliem o desenvolvimento do esporte. 
Este estudo reforça o verificado por SEIPPEL ${ }^{35}$ e ATHERLEY ${ }^{36}$, revelando que as principais dificuldades sentidas pelos dirigentes dos clubes se prendiam com a dificuldade de recrutamento/envolvimento de indivíduos, principalmente colaboradores voluntários para funçôes dirigentes. A densidade demográfica do local onde o clube está implementado exerce efeitos no seu funcionamento, que no caso da ADP estas dificuldades aparecem agravadas ao estenderem-se a atletas, o que reitera as preocupaçóes de GonçALVES et al. ${ }^{13}$ e Heinila ${ }^{24}$. Os Clubes Amadores devem adotar uma gestão de recursos humanos sistemática, a qual é facilitada pela criação de um perfil de colaboradores (características de competências), de acordo com as funções a desempenhar (direção ou outro) para este tipo de organizaçóes e o desenvolvimento de competências nesta área dos dirigentes desportivos ${ }^{11}$.

É de salientar que o fato da AAC-OAF criar uma perspectiva de carreira aos treinadores dos escalóes de formação permite o aumento do seu compromisso organizacional, comparativamente com os classificados como voluntários marginais ${ }^{9}$, que são mais comuns nos Clubes Amadores.

As diferenças existentes entre organizaçóes de diferentes contextos proporcionam experiências singulares aos seus atletas, influenciando o seu processo de desenvolvimento, em características como esforço, compromisso, perseverança, atitudes e valores ${ }^{30}$. Porém, o desenvolvimento parcerias colaborativas e fornecimento de programas desportivos de qualidade podem influenciar o desenvolvimento do jovem indivíduo e, juntamente, o desenvolvimento comunitário ${ }^{31}$. Por isso, acredita-se que será importante continuar a investigar as diferenças contextuais das organizaçóes, quer numa perspectiva macro (e.g., contexto sociocultural), exo (e.g., políticas locais) e micro (e.g., características dos atletas e do seu ambiente próximo), para compreender as suas influências no desenvolvimento dos atletas e da comunidade.

O presente estudo reforça a preocupação sobre as especificidades das características contextuais e próprias dos clubes quando se pretendem definir políticas de promoção do desenvolvimento do indivíduo e da comunidade pelo e no Esporte. De fato, apesar de todas as organizaçóes desportivas estudadas nesta investigaçáo fornecerem a prática desportiva de futebol com escalóes de formação, existem diferenças organizacionais e de relaçôes externas entre os Clubes Amadores e a AAC-OAF. Os Clubes Amadores são estruturas simples, com base no voluntariado e com fins de benefício mútuo, com baixa especialização e formalização no seu funcionamento, sobrevivendo pela "carolice" dos dirigentes, que assumem funções pelo receio de extinção do clube. A AAC-OAF é caraterizado por possuir uma maior estrutura orgânica, dimensão externa, grau de especialização e formalização, apostando no rendimento desportivo e espetacularização. As autoridades locais devem ter atenção às necessidades e dificuldades sentidas pelos Clubes Amadores na angariação dos recursos humanos, financeiros e espaciais. Mesmo existindo semelhanças dos Clubes Amadores a nível organizacional, estes revelam diferenças nas relaçóes externas estabelecidas com as autoridades locais, no que respeita à atribuição de apoios monetários e espaciais, com efeitos na sua capacidade de oferta desportiva e situaçáo financeira. Estes fatores são importantes para a manutenção e desenvolvimento do funcionamento das organizaçóes e, consequentemente, do envolvimento dos jovens na prática desportiva, devendo as entidades governamentais e federativas prestar atenção a tais variáveis. Estas entidades devem apoiar os clubes a desenvolver sistemas de avaliação do seu serviço, a fim de observar os seus benefícios para a sociedade, bem como, o cumprimento das suas metas e finalidades. É fundamental continuar e aprofundar a análise contextual das organizações desportivas contribuindo para o desenvolvimento de políticas e metas do setor público, local e nacional, para o Esporte, bem como, do serviço desportivo.

\section{Abstract}

\section{Comparative analysis of soccer clubs with formation teams from different contexts}

The sport clubs are influenced during their existence and function by the environment where they're implemented, but can influence the individuals that are involved in the club, through organizational culture. Due to the different club context specificities it urges a data necessity about the clubs function, which will allow the implementation of intervention programs. This study pretends to analyse and compare 
three clubs from different contexts. For data, we selected by convenience three clubs, one professional and two amateurs, one of rural area and other from urban area. The AAC-OAF presents differences from the amateur clubs, being more oriented to sport performance/spectacularization. The amateur clubs are based on volunteering, depend more from local policies and authorities and reveal more difficulties in recruit volunteers, mainly, for management. The acceptance of manager's positions in the amateur clubs is due to the fear of extinction the club services. The financial stability of the UCE contributes for changes on organization culture and function. All the clubs present deficiencies in the evaluation process of the programs implementation for youth developmental, recurring more to the competition results.

KEY WoRds: Professional; Amateur; Rural; Urban.

\section{Referências}

1. Gómez S, Opazo M, Martí C. Structural characteristics of sport organizations: main trends in the academic discussion [Internet]. Madrid; 2007 [cited 2014 Abr 14]. Available from: http://papers.ssrn.com/sol3/papers.cfm?abstract_id=1116226.

2. Enjolras B. The commercialization of voluntary sport organizations in Norway. Nonprofit Volunt Sect Q. 2002;31:352-76.

3. European Commission. White Paper on Sport [Internet]. European Commission; 2007 [cited 2014 Abr 14]. Available from: http://ec.europa.eu/sport/white-paper/whitepaper8_en.htm\#2_4.

4. Australian Bureau of Statistics. Sports and physical recreation: a statistical overview. Sydney: Australian Bureau of Statistics; 2012.

5. Damo AS. Do dom à profissão: uma etnografia do futebol de espetáculo a partir da formação de jogadores no Brasil e na França [tese]. Porto Alegre (RS): Universidade Federal do Rio Grande do Sul; 2005.

6. Nichols G, James M. One size does not fit all: implications of sports club diversity for their effectiveness as a policy tool and for government support. Manag Leis. 2008;13:104-4.

7. Thibault L, Slack T, Hinings B. Professionalism, structures and systems: the impact of professional staff on voluntary sport organizations. Int Rev Sociol Sport. 1991;26:83-98.

8. Papadimitriou D. Amateur structures and their effect on performance: the case of Greek voluntary sports clubs. Manag Leis. 2002;7:205-19.

9. Cuskelly G. Volunteer retention in community sport organisations. Eur Sport Manag Q. 2004;4:59-76.

10. Sports England. Sports volunteering in England 2002. Sheffield: Sheffield Research; 2003.

11. Doherty A. Sport volunteerism: an introduction to the special issue. Sport Manag Rev. 2006;9:105-9.

12. Horch HD. Sociological research on sports organizations in the Federal Republic of Germany: an overview. Int Rev Sociol Sport. 1989;24:201-16.

13. Gonçalves CE, Coelho e Silva MJ. Contemporary trends and issues in youth sport in Portugal. In: Coelho e Silva MJ, Malina RM, editors. Children and youth in organized sports. Coimbra: Coimbra University Press; 2004. p.15-30.

14. Mintzberg H. Design options in sport organizations. In: Slack T. Understanding sport organizations: the application of organization theory. Champaign: Human Kinetics; 1997. p.67-90.

15. Skille EÅ. Understanding sport clubs as sport policy implementers: a theoretical framework for the analysis of the implementation of central sport policy through local and voluntary sport organizations. Int Rev Sociol Sport. 2008;43:181-200.

16. Krebs RJ, Santos JO, Ramalho MH, Nazario PF, Nobre GC, Almeida RT. Disposição de adolescentes para a prática de esportes: um estudo orientado pela teoria bioecológica de Bronfenbrenner. Motriz. 2011;17:195-201.

17. Ferreira A, Martinez L. Manual de diagnóstico e mudança organizacional. Lisboa: Editora RH; 2008.

18. Flick U. Métodos qualitativos na investigaçao científica. Lisboa: Monitor; 2002.

19. Mintzberg H. Estrutura e dinâmica das organizaçôes. Lisboa: Dom Quixote; 1995.

20. Seippel Ø. Sport and social capital. Acta Sociol. 2006;49:169-83.

21. Gaskin K. A winning team? The impacts of volunteers in sport [Internet]. London: Institute for Volunteering Research and Volunteering England; 2008 [cited 2014 Abr 14]. Available from: http://sportetcitoyennete.com/revues/ septembre2009/a_winning_team.pdf.

22. Smith RE, Smoll FL, Cumming SP. Effects of a motivational climate intervention for coaches on young athletes' sport performance anxiety. J Sport Exerc Psychol. 2007;29:39-59.

23. Worsley P. Introdução à sociologia. 5a ed. Lisboa: Dom Quixote; 1983. 
24. Heinila K. The sports club as a social organization in Finland. Int Rev Sociol Sport. 1989;24:225-48.

25. Abbott GN, White FA, Charles MA. Linking values and organizational commitment: a correlational and experimental investigation in two organizations. J Occup Organ Psychol. 2005;78:531-51.

26. Cervelló EM, Escartí A, Guzmán JF. Youth sport dropout from the achievement goal theory. Psicothema. 2007;19:65-71.

27. Goodger K, Gorely T, Lavallee D, Harwood C. Burnout in sport: a systematic review. Sport Psychol. 2007;21:127-51.

28. Rocha CM, Turner BA. Organizational effectiveness of athletic departments and coaches' extra- role behaviors. J Issues Intercoll Athl. 2008;1:124-44.

29. Olusoga P, Butt J, Hays K, Maynard I. Stress in elite sports coaching: identifying stressors. J Appl Sport Psychol. 2009;21:442-59.

30. Fraser-Thomas J, Côté J. Understanding adolescents' positive and negative developmental experiences in sport. Sport Psychol. 2009;23:3-23.

31. Vail SE. Community development and sport participation. J Sport Manag. 2007;21:571-96.

32. Cavichiolli FR, Cheluchinhak AB, Capraro AM, Marchi Junior W, Mezzadri FM. O processo de formação do atleta de futsal e futebol: análise etnográfica. Rev Bras Educ Fis Esporte. 2011;25:631-47.

33. Wells MS., Arthur-Banning SG. The logic of youth development: constructing a logic model of youth development through sport. J Park Recreat Adm. 2008;26:189-202.

34. Thiel A, Mayer J. Characteristics of voluntary sports clubs management: a sociological perspective. Eur Sport Manag Q. 2009;9:81-8.

35. Seippel $\varnothing$. The world according to voluntary sport organizations: voluntarism, economy and facilities. Int Rev Sociol Sport. 2004;39:223-32. A

36. Atherley KM. Sport, localism and social capital in rural western Australia. Geogr Res. 2006;44:348-60.

\section{Agradecimentos}

Agradecemos à Fundaçáo para a Ciência e Tecnologia (FCT) de Portugal pela bolsa SFRH/BD/71534/2010, e ao Mestre Matheus Uba Chupel pela colaboração na verificação do texto.

Recebido para publicação: 06/ 09/2013

Revisado: 25/ 10/2014

Aceito: 03/ 11/ 2014 -mail. arturjbsantos@yaho0.com. br 